\title{
La constitución del Consejo Cántabro de la Economía Social: una obligación legal y una oportunidad para la promoción del sector
}

\author{
Luis Ángel Díez Ácimas \\ Técnico de Organismos Autónomos. Administración General del Estado
}

Sumario: 1. Introducción. 2. Antecedentes. 3. Concepto y naturaleza. 4. Funciones. 5. Política de fomento y Consejo cántabro de Economía Social. 5.1. Artículo 129.2 de la Constitución Española de 1978. 5.2. Ley 5/2011, de 29 de marzo, de Economía Social. 5.3. Ley de Cantabria 6/2013, de Cooperativas de Cantabria. 5.4. Ley 44/2015, de 14 de octubre, de Sociedades Laborales y Participadas. 5.5. Conclusiones sobre la política de fomento y la posible contribución del Consejo Cántabro de Economía Social a la misma. 6. Arbitraje cooperativo. 7. Composición. 8. Funcionamiento. 9. Conclusiones. Bibliografía.

Resumen: La Ley de Cooperativas de Cantabria dedica el Capítulo III del Título III a regular el Consejo Cántabro de la Economía Social. Este es un órgano de promoción y difusión del cooperativismo y la economía social. Tiene funciones de carácter consultivo y asesor para las actividades relacionadas con este sector.

La Ley obliga al Gobierno de Cantabria a dictar la norma de organización y funcionamiento de este Consejo, en el plazo de un año desde su entrada en vigor. Este se cumplió el 18 de enero de 2015. Esta norma no se ha dictado aún.

En este estudio, se recuerda esa obligación impuesta al Gobierno de Cantabria; pero, se resalta, al mismo tiempo, el carácter positivo que el funcionamiento del Consejo tendría sobre la política de fomento de la economía social en esta región, contribuyendo decisivamente a su promoción y a conseguir una mayor visibilidad por parte de la sociedad.

Palabras clave: Consejo Cántabro de la Economía Social, organización, funcionamiento, fomento.

Abstract: The Cooperatives Act of Cantabria dedicates Chapter III of Title III to regulate the Cantabrian Council of Social Economy. This is an organ of promotion and diffusion of cooperative system and the social economy. It has consultative and advisory functions for activities related to this sector

The law obliges the government of Cantabria to dictate the rules of organization and functioning of this Council within one year of its entry into force. 
This deadline was fulfilled on January 18,2015 . This rule has not yet been issued.

That obligation imposed on the government of Cantabria is reminded in this study but at the same time, it emphasizes the positive character that the Council's function would have on the policy of promoting the social economy in this region, which will contribute decisively to its promotion and to gain greater visibility for society.

Keywords: Cantabrian Council of Social Economy, organization, functioning, promotion. 


\section{Introducción}

El Capítulo III del Título III de la Ley de Cooperativas de Cantabria (LCCANT) se dedica a la regulación del Consejo Cántabro de la Economía Social (CCES). Esta es la primera vez que la normativa autonómica regula un órgano de este tipo, ya que en la Comunidad Autónoma de Cantabria no se había previsto hasta ahora la existencia de un consejo especializado en materia de cooperativismo, en concreto; o, de economía social, en general.

De acuerdo con el artículo 142 de la ley, este se configura como un órgano de promoción y difusión del cooperativismo, dotado de funciones de carácter consultivo y asesor para las actividades relacionadas con la economía social. Se le atribuyen, también, las tareas de colaboración y coordinación entre el movimiento asociativo y la administración autonómica.

La propia ley obliga a que en el plazo de un año, desde la entrada en vigor de la misma, el Gobierno de Cantabria dicte la norma de organización y funcionamiento de este Consejo. Este plazo se cumplió el 18 de enero de 2015, sin que hasta el momento se haya aprobado tal normativa ${ }^{1}$.

La creación tendría mucha más trascendencia que la de dar cumplimiento a esa obligación legal, porque consideramos que este puede ser un instrumento básico para la mejora de las actuaciones de fomento y difusión de la economía social en Cantabria. Un campo en el que creemos que cabe hacer una labor importantísima y que puede ser liderada por este Consejo.

Una vez aprobada la normativa de organización y funcionamiento, y constituido el CCES, se debe conseguir un funcionamiento regular y acertado de este, donde se cuente con un alto índice de compromiso y cooperación de todos los partícipes del mismo, para realizar una función de fomento y difusión de la economía social con un grado de intensidad superior al que se ha realizado hasta ahora, y que consiga mejorar la presencia de este sector en la sociedad de Cantabria.

1 La Disposición Final Primera de la LCCANT establece la obligación de dictar esta norma y la reguladora del Registro de Sociedades Cooperativas de la Comunidad Autónoma de Cantabria, en el referido plazo de un año desde la entrada en vigor de la misma. La norma del Registro tampoco ha sido aprobada. 


\section{Antecedentes}

En la normativa estatal, el artículo $13^{2}$ de la Ley 5/2011, de 29 de marzo, de Economía Socia (LES), regula el Consejo para el Fomento de la Economía Social. El apartado 5 prevé que su funcionamiento y composición serán objeto de desarrollo reglamentario. Este aún no ha se ha producido, pese al tiempo transcurrido desde la promulgación de la citada ley. No obstante, la disposición transitoria primera de la misma, prevé que hasta la entrada en vigor de esta normativa, el Consejo se regirá por lo dispuesto en la disposición adicional segunda de la Ley 27/1999, de 16 de julio, de Cooperativas. De esta manera, se consigue que no haya un intervalo de tiempo en el que no exista un consejo de esta naturaleza en el ámbito estatal.

Evidentemente, entendemos que se debe desarrollar el modelo previsto en la LES, aunque, como decimos, no exista vacío de un órgano de este tipo. Además, es más correcto que se regule en la normativa general de economía social, una vez aprobada una ley que aglutina a todas las figuras incluidas en este concepto, y no en una norma de un tipo empresarial específico, como es la Ley de Cooperativas.

A nivel autonómico, es habitual la existencia de consejos de economía social o cooperativismo ${ }^{3}$. Las funciones y objetivos propuestos son similares en todos los casos, aunque el grado de actividad y efectividad de los mismos es muy variado.

Otros órganos, sin ser específicos de economía social, han realizado funciones similares a las previstas para este tipo de consejos en ámbitos más generales; pero incluyendo actuaciones en esta materia. Nos referimos básicamente, en el ámbito estatal, al Consejo Económico y Social (CES), creado por la Ley 21/1991, de 17 de julio, como órgano consultivo del Gobierno en materia socioeconómica y laboral, que cuenta entre sus miembros con cuatro representantes de la economía social ${ }^{4}$.

En la Comunidad Autónoma de Cantabria, el Consejo Económico y Social fue creado por la Ley de Cantabria 6/1992, de 30 de junio; pero,

2 Se renumera por el artículo 3.6 de la Ley 3/2015, de 9 de agosto, por la que se modifica y actualiza la normativa en materia de autoempleo y se adoptan medidas de fomento y promoción del trabajo autónomo y la economía social. Anteriormente, era el artículo 9.

3 Además, de Cantabria, solamente Canarias no cuenta con un órgano de este tipo. El último en regularse ha sido el de Asturias, por Decreto 56/2016, de 5 de octubre, por el que se regula la organización y funcionamiento del Consejo Asturiano de la Economía Social. Su existencia estaba prevista en la Ley del Principado Asturias 4/2010, de 29 de junio, de Cooperativas.

4 La composición del CES es de 60 miembros más su presidente. 
fue suprimido por el artículo 15 de la Ley de Cantabria 2/2012, de 30 de mayo, de Medidas Administrativas, Económicas y Financieras para la ejecución del Plan de Sostenibilidad de los Servicios Públicos de la Comunidad Autónoma de Cantabria. Durante su existencia no tuvo representación de la economía social, pese a que en su artículo 2.4 se refería expresamente a este sector 5 .

En las Comunidades Autónomas que cuentan con Consejo Económico y Social (con ésta u otra denominación) es habitual que haya consejeros en representación de la economía social6. Por lo que entendemos que si, en un futuro próximo, como proponen algunos grupos parlamentarios, se recupera en Cantabria la existencia del CES, debería de incluirse a la representación de este sector en el mismo, con independencia de la creación efectiva del CCES, para que el sector pueda participar de los debates sobre asuntos económicos, demográficos, de fomento de empleo, de desarrollo rural y local, de igualdad de oportunidades, ... todos ellos de importancia para la sociedad en su conjunto y en la que sus opiniones pueden ser, en algunos casos, muy relevantes, por el conocimiento de la realidad y el entorno social donde están enclavadas las empresas de economía social.

\section{Concepto y naturaleza}

El asociacionismo cooperativo tiene dos manifestaciones básicas y ambas son recogidas en la LCCANT. Por un lado, estaría la defensa de intereses económicos y sociales de las cooperativas y la prestación de servicios de todo tipo a éstas (para ello, la ley prevé la existencia de uniones y federaciones); y, por otro, estaría la representación institucional y el diálogo con la Administración Pública. Reflejos de esta vertiente son la Confederación de Cooperativas de Cantabria, que también participaría del otro bloque de funciones citado anteriormente; y, especialmente, el CCES, que excede del mundo del cooperativismo (incluye representación de otras formas empresariales) y del asociacionismo (in-

5 Artículo 2.4 de la ley de Cantabria 6/1992, de 30 de junio, de creación del Consejo Económico Social. «A efectos de hacer más efectiva la participación de los distintos sectores económicos y sociales del Consejo Económico y Social, el Consejo de Gobierno tomará en consideración para la propuesta de expertos de reconocido prestigio a aquellos sectores de economía social, así como a entidades o asociaciones e instituciones con incidencia en el ámbito económico y social de la comunidad cántabra».

6 Al menos, Andalucía, Asturias, Castilla y León, Cataluña, Extremadura, Murcia, País Vasco, y Valencia cuentan con representantes de la economía social en su CES. 
cluye en su composición a otros actores de procedencia diversa, como son la Administración y los expertos en la materia). No obstante, una parte importante de sus miembros, proceden, como veremos más adelante, del mundo asociativo de las diferentes formas empresariales de la economía social.

La primera decisión que debía tomar la ley, respecto a la configuración del CCES, era decidir si se regulaba un consejo exclusivo para el sector cooperativista (al recogerse su creación en una ley que regula las cooperativas y sus entidades asociativas) u optar por una figura en la que estuviese representado el conjunto empresarial de la economía social. Como sabemos, por la propia denominación del Consejo, se opta por la segunda de las alternativas expuestas.

Pese a configurarse como un órgano aglutinador de la economía social de carácter empresarial, la primera manifestación que hace el artículo 142.1 va referida al cooperativismo, definiendo al CCES como su órgano máximo de promoción y difusión, para añadir, a continuación, que tiene funciones de carácter consultivo y asesor para las actuaciones relacionadas con la economía social. Parece desprenderse del texto referido que la ley quiere hacer un guiño al sector cooperativo, al citarlo expresamente y con anterioridad al conjunto de la economía social. El motivo de esta doble referencia al sector, destacando a las cooperativas sobre el resto de entidades, tal vez haya que buscarlo, por un lado, en que la previsión de este Consejo se hace en la ley dedicada a regular las sociedades cooperativas; $y$, de otro, a la relevancia del cooperativismo, que tiene superior implantación en la realidad económica actual y mayor tradición histórica que el resto de empresas de economía social.

Con esta opción por un único Consejo, se evita una posible duplicidad futura de órganos. Si este sólo se dedicase al cooperativismo, podría plantearse en el futuro, por parte de las entidades asociativas de otras fórmulas empresariales de economía social la reclamación de la creación de otro órgano consultivo dedicado al fomento de esas otras realidades de la economía social, y solicitando su participación en el mismo. Esta situación, que se ha producido en alguna comunidad autónoma ${ }^{7}$, no tiene ningún sentido que pueda plantearse en el futuro en una región de reducida dimensión y bajo grado de implantación de

7 La Ley 4/2002, de 11 de abril, de Cooperativas de Castilla y León dispone en su artículo 145 la creación del Consejo Superior Regional para el Fomento del Cooperativismo. El Decreto 104/2004, de 23 de septiembre, regula su organización y funcionamiento. Posteriormente, entró en vigor el Decreto 11/2009, de 29 de enero, por el que se crea el Consejo Regional de Economía Social de Castilla y León. 
la economía social como es el caso de Cantabria; por lo que creemos que la opción por esta fórmula de un único Consejo es acertada.

Entendemos que, además, hay otro motivo que hace razonable la confluencia en un solo Consejo de las diferentes empresas de economía social. En Cantabria, las tres asociaciones empresariales de economía social que conocemos, cuentan entre sus miembros, tanto con cooperativas, como con sociedades laborales, por lo que no resultaría adecuado que las mismas entidades asociativas estuviesen presentes en dos órganos, en uno representando a las sociedades cooperativas; y, en otro, a las sociedades laborales.

En el artículo 142 de la ley, se establece la configuración del CCES, con las notas que hemos referido anteriormente:

- Órgano máximo en materia de promoción y difusión del cooperativismo.

- Desarrolla funciones de carácter consultivo y asesor para las actividades relacionadas con la economía social.

- Se le atribuyen, también, las tareas de colaboración y coordinación entre el movimiento asociativo y la administración autonómica.

La adscripción de este órgano recae en la consejería con competencias en materia de economía social ${ }^{8}$.

Como conclusión de lo indicado, podemos señalar que el CCES se configura como un órgano público, adscrito a una consejería; pero, no integrado en la estructura administrativa de la Comunidad Autónoma (y no sometido, por tanto, a la jerarquía administrativa), colegiado y de carácter consultivo y asesor.

\section{Funciones}

Las funciones que le corresponden al CCES se determinan en el artículo 143 de la Ley:

- Facilitar y colaborar en la investigación, planificación y ejecución de los programas de desarrollo y fomento del cooperativismo, así como promover la educación y formación cooperativa.

- Elaborar propuestas y dictámenes en relación con las cuestiones que afecten al cooperativismo.

8 En la actualidad, Consejería de Economía, Hacienda y Empleo. 
- Emitir informe sobre los proyectos de disposiciones legales y reglamentarias y demás normas que afecten directamente a la economía social o a sus organizaciones, así como procurar su difusión.

- Conciliar y ejercer el arbitraje en las cuestiones litigiosas que se planteen entre cooperativas, entre estas y sus socios, o en el seno de las mismas entre sus socios, cuando ambas partes lo soliciten o bien estén obligadas a tenor de lo establecido en sus estatutos sociales.

- Colaborar en la elaboración de proposiciones sobre cualquier disposición legal o reglamentaria que afecten a entidades de la economía social.

- Realizar estudios sobre cuestiones y problemas que afecten a la economía social.

El artículo 129.6 de la LCCANT, al regular el régimen jurídico de las cooperativas mixtas parece atribuir otra función a este Consejo ${ }^{9}$, al establecer que en el momento de la configuración, constitutiva o por modificación, de estas cooperativas, el Consejo podrá autorizar la previsión estatutaria de la repartibilidad del fondo de reserva obligatorio en caso de liquidación, respetando las demás normas de adjudicación del haber social previstas en la ley.

Podemos concluir, de las funciones que la LCCANT encomienda al CCES, que este tiene tres grandes áreas de actuación, que son las siguientes:

- Contribuir al fomento del cooperativismo. Incluida la promoción de la educación y formación cooperativa.

- Conciliar y ejercer el arbitraje, cuando proceda.

- Emitir informe sobre los proyectos legislativos y reglamentarios, e incluso colaborar en la elaboración de los mismos. Contribuir a la difusión de dichas normas. Además, dictará informes y dictámenes y realizará estudios sobre todas las materias que le son propias.

A continuación, realizaremos algunas reflexiones sobre las dos primeras funciones que, creemos, constituirían la esencia de este órgano,

9 El precepto se refiere al Consejo de Fomento de la Economía Social; pero, cabe entender que se trata de un error de la ley. Esta denominación coincide con la del correspondiente órgano en el ámbito estatal, pero no corresponde a una ley autonómica establecer funciones a un órgano que excede de su ámbito. En su caso, el Reglamento de Organización y Funcionamiento del CCES deberá resolver si ésta es una competencia del mismo. 
ya que la tercera de ellas tiene un carácter más formal y propio de su actuación ordinaria.

\section{Política de fomento y Consejo Cántabro de Economía Social}

Si hacemos un repaso por la diferente normativa reguladora de la economía social, en general, o de las diferentes formas empresariales que conforman esta, nos encontramos con una referencia constante al fomento de este sector y a la imposición de obligaciones al respecto a los poderes públicos. Veamos algunas de estas normas.

\subsection{Artículo 129.2 de la Constitución española de 1978 (CE)}

La primera aproximación la encontramos en este precepto constitucional, que ordena tres actuaciones a los poderes públicos ${ }^{10}$ :

1. La promoción de las diversas formas de participación en la empresa.

2. El fomento mediante una legislación adecuada de las sociedades cooperativas.

3. El establecimiento de las medidas que faciliten el acceso de los trabajadores a la propiedad de los medios de producción.

Nos centraremos en los dos últimos mandatos de este precepto. En lo que respecta al cumplimiento de la obligación impuesta a los poderes públicos de fomentar las sociedades cooperativas, mediante una legislación adecuada, podemos constatar la existencia de una amplia normativa en la materia. Respecto a la regulación general de este tipo de sociedades, contamos con una Ley de Cooperativas estatal (Ley 27/1999, de 16 de julio), y dieciséis leyes autonómicas ${ }^{11}$. Además, de una legislación específica sobre cooperativas de crédito (básicamente la Ley 13/1989, de 26 de mayo) o una regulación del régimen fiscal propio de estas sociedades (Ley 20/1990, de 19 de diciembre, de Régimen Fiscal de las Cooperativas). El análisis de estas regulaciones, nos podría llevar al debate de si esa legislación es "adecuada», como

10 Se pueden consultar unas reflexiones muy interesantes respecto a este precepto, en CALVO ORTEGA, R. "Las figuras de la economía social en la Constitución Española de 1978». CIRIEC-España, n. ${ }^{\circ}$ 47. 2003. Pp. 159-174.

11 Únicamente, la Comunidad Autónoma de Canarias no dispone de ley propia en materia de sociedades cooperativas. 
exige la C.E; pero, evidentemente, este no es el lugar para plantear esa discusión.

En el último inciso de este artículo, se propone el establecimiento de las medidas que faciliten el acceso de los trabajadores a la propiedad de los medios de producción y se identifica esta participación con la propiedad de la empresa. Este precepto ofrece extraordinarias posibilidades para la actuación política, tanto en la selección de los mecanismos de participación como en la determinación cualitativa de los mismos.

Esto se plasma en la promoción de fórmulas fundamentalmente de carácter económico-financiero que contribuyan a la superación de los condicionantes que limitan el acceso a la propiedad de esos bienes y faciliten el acceso al accionariado por parte de los trabajadores. Manifestaciones características de este proceso son las diferentes legislaciones que se han promulgado para regular las sociedades laborales $y$, ahora, las sociedades participadas, cuya finalidad es conseguir nuevos modelos de creación de empleo y fomentar la participación de los trabajadores en la empresa, dando cumplimiento, así, a este mandato constitucional.

\subsection{Ley 5/2011, de 29 de marzo, de Economía Social (LES)}

Esta ley ha contribuido decisivamente a acotar y visualizar, según Montesinos Oltra12; un sector de la realidad social de cuya importancia difícilmente puede dudarse, tanto en términos cuantitativos como, sobre todo, cualitativos, que son los que permiten considerarlo un «polo de utilidad social» como se señala en el Informe de la Subcomisión para el Fomento de la Economía Social creada en el seno de la Comisión de Economía y Hacienda del Congreso de los Diputados y justifican el reconocimiento de tratamientos favorecedores o promocionales desde la perspectiva de la actividad financiera de las Administraciones Públicas.

Para las políticas de fomento de la economía social en España, esta ley es un punto de inflexión; realmente, abre, al menos teóricamente, una nueva etapa en esta materia. Y, decimos teóricamente, porque está pendiente una necesaria y apasionante labor de desarrollo de la LES.

12 MONTESINOS OLTRA, S., "La Ley de Economía Social, interés general y regímenes tributarios especiales». CIRIEC-España, Revista Jurídica n. ${ }^{\circ} 23.2012$, pp. 1-27. 
Destacan dos aspectos en los que se aprecia el nuevo marco en el que se mueve este sector:

a) Reconocimiento de este sector socioeconómico como un interlocutor social en los procesos de elaboración de las políticas públicas (artículo 7).

b) Concepción de una amplia gama de políticas de fomento de la economía social. Sobre este último punto, esta ley establece cuatro grupos de políticas, clasificadas por Chaves $^{13}$ de la siguiente manera (artículo 8):

1. Medidas institucionales dirigidas a eliminar obstáculos jurídicos al desarrollo de la economía social. En particular, la simplificación de los trámites administrativos para la creación de entidades de economía social, la revisión de la normativa a fin de suprimir las limitaciones de estas entidades de forma que éstas puedan operar en cualquier actividad económica sin trabas injustificadas. La legislación no es neutra, como demuestra la creación de sociedades laborales tras la ley de 1997 que permite la forma limitada o las leyes de cooperativas que admiten su creación con dos socios. Debe hacerse un esfuerzo normativo de simplificación de las exigencias para constituir empresas y gestionar éstas; pero, sin poner en peligro los elementos definidores de los modelos de hacer empresas desde la economía social.

2. Medidas de carácter cognitivo dirigidas a difundir, formar, investigar e innovar en este campo. Las tareas a realizar son muy variadas, tales como promover los principios y valores de esta; promocionar la formación y readaptación profesional en el ámbito de estas entidades; introducir referencias a la economía social en los planes de estudio en todos los niveles educativos; y facilitar el acceso a los procesos de innovación tecnológica y organizativa a los emprendedores de las entidades de economía social.

3. Medidas institucionales dirigidas a establecer un órgano público de fomento de la economía social. Se confirma al actual Ministerio de Empleo y Seguridad Social en esta tarea, y a un órgano de participación e interlocución social en materia de economía social, el Consejo de Fomento de

13 CHAVES, R.: «La loi espagnole de l'économie sociale», Revue Internationale de l'Économie Sociale. 2011. 
la Economía Social, en el que están representadas las administraciones estatal, regional y municipal, los sindicatos, las entidades representativas de la economía social de ámbito estatal, así como expertos y del que hemos hablado anteriormente.

4. Medidas institucionales de inclusión explícita de la economía social en diversas políticas sectoriales. En concreto, en las políticas activas de empleo, especialmente aquellas a favor de los sectores más afectados por el desempleo (mujeres, jóvenes y parados de larga duración), en las políticas de desarrollo rural, de servicios sociales a personas dependientes, así como la integración de las empresas de la economía social en las estrategias para la mejora de la productividad y la competitividad empresarial.

Esta ley considera empresas de economía social, entre otras, a cooperativas, sociedades laborales, empresas de inserción y centros especiales de empleo, que son a las que la LCCANT garantiza representación en el CCES.

\subsection{Ley de Cantabria 6/2013, de Cooperativas}

Habitualmente, las leyes de cooperativas fijan como objeto de las mismas, no sólo la regulación de este tipo de sociedades, sino que incluyen las medidas básicas de fomento de estas.

Para ello, imponen una serie de obligaciones a las Administraciones Públicas, cuyo grado de cumplimiento, en ocasiones, deja mucho que desear en la plasmación de las políticas públicas al respecto; y, en otras, se hacen declaraciones que encuentran difícil concreción en la legislación específica de cada materia. Esto nos lleva a entender que estas medidas son informadoras de la legislación específica de cada materia que debe contemplar, con carácter general, la existencia de las cooperativas, sus peculiaridades y la obligación constitucional de dotarlas de una legislación adecuada. Esta es la única manera de hacer efectivo el mandato constitucional de dotar de una legislación adecuada a la sociedad cooperativa. Una Ley de Cooperativas, por buena que sea, no cumple en sí misma, con ese carácter de legislación adecuada, salvo que se acompañe de otras normas sectoriales que contemplen esta figura.

Siguiendo dicha línea la LCCANT, establece en su artículo 1 que ésta tiene por objeto la regulación jurídica de las sociedades cooperativas de Cantabria y el fomento de las mismas. 
No podemos olvidar que al hablar de la LCCANT, estamos analizando normativa autonómica; y, aunque la ley proclame que su objeto es el fomento de las sociedades cooperativas, el legislador autonómico no puede hacer uso de algunas de las principales herramientas que pueden perseguir tal finalidad, al carecer en determinadas materias de competencia legislativa (tales como fiscal, laboral o de seguridad social $^{14}$, que pueden ofrecer ventajas patrimoniales a este tipo de sociedades).

Tras esa declaración inicial del artículo 1, dedica el capítulo I del título III de la ley a regular el Fomento del Cooperativismo. Se trata de los artículos 134 y 135 . El primero de ellos, fija el criterio general y el segundo las medidas de fomento.

En el artículo 134, se hacen dos declaraciones fundamentales, la primera dirigida a la Comunidad Autónoma de Cantabria y la segunda a su Gobierno.

1. La Comunidad Autónoma de Cantabria, en cumplimiento del artículo 129.2 de la CE y del 57.4 de su Estatuto de Autonomía ${ }^{15}$, "asume la tarea de promoción, estímulo y desarrollo de las sociedades cooperativas y de sus estructuras de integración económico-empresarial y representativas, cuya libertad y autonomía garantiza». Como se puede ver, no sólo fomentará las sociedades cooperativas y sus agrupaciones con finalidad puramente empresarial; sino, también, las estructuras asociativas representativas de este sector, garantizando, como no puede ser de otra manera, la independencia de éstas.

2. La segunda va dirigida al Gobierno de Cantabria. Aquí, señala cuál será la consejería competente, con carácter general, en materia de cooperativismo, reconociendo las facultades que puedan tener otras consejerías en relación al cumplimiento de la legislación específica que les corresponda aplicar.

Esta previsión se ve completada con la Disposición Adicional Séptima, que bajo la rúbrica «Atribución de competencias» indica cuál será

14 Constitución Española. Artículo 149.1. 14. ${ }^{a}, 7^{a}{ }^{a}, 17 .{ }^{a}$, respectivamente.

15 Ley Orgánica 8/1981, de 30 de diciembre, de Estatuto de Autonomía para Cantabria (redacción dada por L.O. 11/1998, de 30 de diciembre). El artículo 57.4 establece «La Comunidad Autónoma de Cantabria, como poder público, podrá hacer uso de las facultades previstas en el apartado 1 del artículo 130 de la Constitución, y podrá fomentar mediante acciones adecuadas, las sociedades cooperativas. Asimismo, de acuerdo con la legislación del Estado en la materia, podrá hacer uso de las demás facultades previstas en el apartado 2 del artículo 129 de la Constitución». 
el centro directivo del Gobierno de Cantabria competente para ejecutar los programas de promoción y fomento de diferentes figuras de economía social16.

En el artículo 135, bajo la rúbrica de «medidas de fomento» contiene seis tipos de enunciados claramente diferenciados por su materia y objetivos:

- Encomienda general de promoción y desarrollo de sociedades cooperativas.

- Fomento de la formación.

- Promoción de cooperativas destinadas a satisfacer necesidades de determinados colectivos.

- Compromiso con la igualdad de género.

- Medidas concretas para todas las sociedades cooperativas o para alguna clase determinada de ella.

- Reducciones y bonificaciones de aranceles notariales.

Por último, se regula el CCES, objeto del presente análisis, en los artículos 142 y 143, como órgano básico para la política de fomento del cooperativismo y de la economía social, paralelo al Consejo estatal regulado en la LES y del que hablamos anteriormente.

\subsection{Ley 44/2015, de 14 de octubre, de Sociedades Laborales y Participadas (LSSLLyPP)}

Esta ley pretende actualizar la regulación de las sociedades laborales como empresas de economía social y, por primera vez, se afronta en España la regulación de las sociedades participadas. Ambas son manifestación de la obligación constitucional de favorecer el acceso de los trabajadores a la propiedad de los medios de producción.

En el articulado se contempla alguna medida fiscal en favor de las sociedades laborales y la disposición adicional cuarta se dedica a las medidas de fomento para la constitución de estas y la creación de empleo. Establece que serán de aplicación a los socios trabajadores de las sociedades laborales todos los beneficios que, en el ámbito de em-

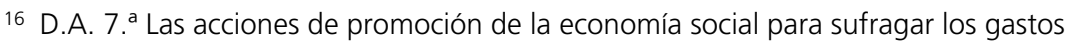
de funcionamiento de las asociaciones de cooperativas, sociedades laborales y empresas de inserción de ámbito autonómico, así como los programas de fomento de empleo específicos para estos tres tipos de empresas, que se desarrollen por la Administración de la Comunidad Autónoma de Cantabria, serán competencia de la Dirección General de Trabajo o de la que pudiera asumir las competencias de ésta. 
pleo y de la seguridad social, y en desarrollo de la Ley 5/2011, de 29 de marzo, de Economía Social, tengan por objeto impulsar la realización de actuaciones de promoción, difusión y formación de la economía social (tales como bonificaciones de cuotas de Seguridad Social, capitalización de la prestación por desempleo...).

\subsection{Conclusiones sobre la política de fomento y la posible contribución del CCES a la misma}

No podemos obviar que existen voces discrepantes con la existencia de medidas específicas favorecedoras de las empresas de economía social, especialmente en el caso de las cooperativas, por ser éstas las que tienen un régimen fiscal propio; pero, los motivos para que estas medidas existan son claros. Estas sociedades gozan de principios y valores (gestión democrática, prioridad de la persona sobre el capital...), así como de ventajas y potencialidades (creación de empleo estable y de calidad, fijación de población al territorio, generación de cohesión social, contribución al desarrollo local...) que las hacen merecedoras de un tratamiento específico. Así, lo reconoce el preámbulo de la Ley 31/2015, de 9 de septiembre, por la que se modifica y actualiza la normativa en materia de autoempleo y se adoptan medidas de fomento y promoción del trabajo autónomo y de la economía social17, al reconocer que la economía social es fuente de creación de empleo estable, de calidad y no deslocalizable y es una importante plataforma de acceso al empleo para aquellos que, por sus especiales circunstancias, encuentran mayores dificultades de inserción laboral y/o que se encuentran en riesgo de exclusión social. Constituyen, añade, un elemento clave de cohesión social muy necesario tras la larga crisis que ha atravesado nuestro país.

Para confirmar que estas empresas pueden tener un régimen fiscal favorable sin que sean consideradas ayudas de estado (prohibidas por la normativa comunitaria), Calvo Ortega ${ }^{18}$, hablando concretamente de sociedades laborales, explica que estas prácticas no son ilegales cuando no se favorece a empresas o producciones para falsear la competencia y se trata de una fiscalidad horizontal para un grupo genérico de empresas no vinculados a un territorio ni a una producción concreta.

17 Esta ley modifica el artículo 9 de la Ley 5/2011, de 29 de marzo, de Economía Social, estableciendo incentivos a la incorporación de trabajadores a entidades de economía social.

18 CALVO ORTEGA, R., "Sociedades Laborales». Cuadernos Civitas. Editorial Aranzadi. Cizur Menor 2013, pp. 69-78. 
La Administración General del Estado, así como las Administraciones de las Comunidades Autónomas con competencias en materia de economía social deben elaborar programas estructurados de fomento de la economía social, no adoptar medidas dispersas, inconexas y reiterativas, como ocurre habitualmente, aunque no hayan demostrado su utilidad. Se debe partir del análisis de los resultados de las medidas implementadas con anterioridad y de la fijación de los objetivos que se pretenden conseguir para determinar las medidas que se deben ejecutar en el futuro.

Estas medidas, una vez constatada su eficacia, tienen que ser estables en el tiempo y no estar sujetas a eventualidades económicas o cambios políticos, para ofrecer seguridad a los potenciales promotores de este tipo de empresas de cuál va a ser la actitud de las entidades públicas respecto a sus proyectos empresariales. En la evaluación de actuaciones y propuesta de medidas puede ser muy relevante la aportación, en su día, del CCES.

Para conseguir que las figuras empresariales de economía social calen en el mundo del emprendimiento hay que lograr un mayor conocimiento de las mismas, tanto por parte de los trabajadores y sus representantes, como por los potenciales emprendedores futuros, es decir, los estudiantes universitarios y de enseñanzas medias. Es necesario dar a conocer estas formas empresariales de economía social a los profesionales que asesoran a los potenciales emprendedores, ya que los prescriptores de formas jurídicas empresariales no ofrecen estas fórmulas, habitualmente, a las personas que se acercan a ellos con un proyecto empresarial.

También, sería necesaria la formación específica de los socios trabajadores, ya que ellos son los responsables de fijar los criterios de gestión y los objetivos de su empresa, además de conocer en profundidad el modelo empresarial por el que han optado.

En los programas de formación y difusión vemos constantemente la celebración de congresos, seminarios, encuentros, cursos, ... en los que los participantes son de forma reiterada los estudiosos del tema, los dirigentes del movimiento asociativo o de las empresas de economía social más importantes, los responsables de la materia en las administraciones públicas; pero, no acceden a ellos los promotores de empresas asociativas, los que antes denominábamos prescriptores de formas jurídicas empresariales (asesores, agentes de desarrollo local, orientadores de empleo, personal de las Cámaras de Comercio...) que son los que tienen la llave para la creación efectiva de empresas de economía social.

Tanto la LES como las leyes de cooperativas reclaman la enseñanza del cooperativismo y la economía social en los diferentes niveles educa- 
tivos. Esto es algo que está pendiente y parece que aún muy lejana su consecución. Se llega a un puñado de centros de enseñanza secundaria a los que se acercan las entidades asociativas del sector a presentar estos modelos empresariales y a un reducido número de centros universitarios que realizan acciones de difusión, normalmente financiadas con cargo a programas públicos de fomento; pero, no se introduce el estudio de las fórmulas empresariales de economía social, salvo muy loables excepciones, en los programas educativos.

A la vista de los últimos comentarios vertidos, resulta necesario que el CCES trabaje con los colegios profesionales, con las autoridades educativas, con la Universidad,... para conseguir una mejor penetración de la economía social en estos ámbitos.

Por otro lado, tenemos que valorar que las medidas que existen actualmente, han visto claramente reducidas las posibles ventajas competitivas para estas empresas. Así, la capitalización de la prestación por desempleo prevista en el Real Decreto 1044/1985, de 19 de junio, por el que se regula el abono de la prestación por desempleo en su modalidad de pago único por el valor actual de su importe, como medida de fomento de empleo, se ha generalizado para el inicio de la actividad profesional por parte de los trabajadores autónomos. Lo mismo podemos decir de la libertad de amortización de los elementos del inmovilizado material en los cinco primeros años de existencia de las sociedades laborales, que se ha generalizado a las empresas de pequeña dimensión, o la diferencia que había en 1990, cuando se aprobó el régimen fiscal de las cooperativas, entre el tipo general del Impuesto de Sociedades y los tipos de aplicación a las cooperativas; diferencia que hoy se ha reducido considerablemente.

Con estos datos, podemos concluir que se ha producido una pérdida de las ventajas competitivas que podían tener en otra época las empresas de economía social y que aconsejan una revisión de las políticas de fomento de éstas; pero, insistimos, que se deben adoptar medidas que resulten realmente eficaces para alcanzar el objetivo de conseguir ofrecer una imagen atractiva de las empresas de economía social a los emprendedores; y, en este objetivo, la actuación conjunta de todos los actores implicados, a través del CCES, puede ser vital.

\section{Arbitraje cooperativo}

Estimamos necesario efectuar unas reflexiones sobre la función del arbitraje, figura que no goza de arraigo en el cooperativismo cántabro y que se encomienda al CCES. Esta materia deberá ser, necesa- 
riamente, objeto de desarrollo específico para que pueda ser efectivo el ejercicio de esta función.

Antes de entrar a analizar el tema, queremos comentar un problema interpretativo que se ha originado al respecto de la regulación del arbitraje cooperativo en la LCCANT. Por un lado, en el artículo 15.1.m) establece que en el contenido mínimo de los estatutos se incluirá obligatoriamente la "cláusula de sometimiento al arbitraje cooperativo». Por otro lado, el artículo 143.1.d) al fijar las funciones del CCES, establece que corresponde a este «conciliar y ejercer el arbitraje en las cuestiones litigiosas que se plantean entre cooperativas, entre estas y sus socios, o en el seno de las mismas, entre sus socios, cuando ambas partes lo soliciten o bien estén obligadas a tenor de lo establecido en sus estatutos sociales». De este precepto se deriva claramente el carácter voluntario de incluir en los estatutos la obligación de acudir a la conciliación o arbitraje del CCES, lo que puede parecer contradictorio con la previsión, antes referida, del artículo 15.1. Para solventar esto, creemos que en una futura modificación de la LCCANT se debe aclarar esta cuestión definitivamente; pero, mientras tanto, una interpretación conjunta de ambos preceptos nos puede llevar a entender que la opción del arbitraje no es obligatoria para la cooperativa: y, por tanto, no es necesaria su inclusión imperativa en sus estatutos sociales; pero, si la cooperativa opta por regular el acceso al arbitraje, este deberá ser necesariamente el modelo regulado por el artículo 143 de la LCCANT.

Se puede definir el arbitraje como la institución heterocompositiva mediante la cual, los particulares, libremente; $y$, en virtud del principio de la autonomía de la voluntad, deciden no acudir a los órganos jurisdiccionales ordinarios sino a uno o varios árbitros como medio para resolver sus conflictos, siempre que se trate de cuestiones de su libre disposición; y, cuyo pronunciamiento, aceptado previamente por los litigantes, alcanzará la misma eficacia que si el asunto hubiera sido resuelto por la Administración de Justicia, esto es, como cosa juzgada y ejecutoriedad ${ }^{19}$.

En la normativa sobre cooperativismo, encontramos diferentes fórmulas de afrontar el tema del arbitraje. Así, en la Ley 27/1999, de 16 de julio, de Cooperativas, no se crea ningún tipo de arbitraje administrativo. En su disposición adicional décima hace una remisión a la nor-

19 MARTÍ MIRAVALLS, J. «El arbitraje cooperativo. El caso valenciano», CIRIEC n. ${ }^{\circ}$ 14. 2003. pp. 83-129. Extrae esta definición de la conjunción de los artículos 1, 11, 37 y 53 de la Ley 60/2003, de Arbitraje. 
mativa general sobre arbitraje. Esta remisión debe ser entendida actualmente a la Ley 60/2003, de 23 de diciembre, de Arbitraje.

En la normativa autonómica, el modelo es variado. En algunas legislaciones se opta porque la competencia radique exclusivamente en el correspondiente consejo autonómico (Comunidad Valenciana, Extremadura, Cataluña, País Vasco), y en otras se deja en manos de las entidades asociativas (Aragón, Baleares, La Rioja y Castilla y León). Constituye un caso particular Galicia, ya que su normativa opta por "compartir» la competencia en conciliación (puede ser ejercida por el Consello Galego de Cooperativas o las uniones, federaciones o confederaciones de cooperativas).

El objeto del arbitraje deberá ser el interés material cooperativo del conflicto, es decir, que implique consecuencias materiales para el funcionamiento de la cooperativa, al afectar a ésta o a los socios de la misma en tal condición ${ }^{20}$, por lo tanto, la cuestión litigiosa deberá suscitarse entre cooperativas, entre cooperativas y sus socios 0 , finalmente, entre los socios de una cooperativa.

La LCCANT opta por otorgar esta competencia al CCES. Este órgano puede administrar arbitrajes; pero, para ello, deberá dotarse de un régimen reglamentario. La mayor parte de las comunidades autónomas han optado por una regulación emanada de sus gobiernos, con forma de decreto. En cambio, el País Vasco ha regulado el sistema arbitral por medio de un reglamento interno del propio Consejo Superior de Cooperativas de Euskadi. En el caso de Cantabria, se opte por una fórmula u otra, será preciso, como hemos referido anteriormente, la aprobación de una norma para que realmente pueda el CCES administrar los arbitrajes cooperativos ${ }^{21}$. $Y$ no podemos olvidar que esta normativa deberá ser estrictamente respetuosa con la legislación estatal sobre arbitraje.

En la regulación que se haga del arbitraje sería conveniente que se contemplase expresamente la mediación, ya que esta figura parece particularmente indicada en el contexto de las cooperativas, de clara inspiración democratizadora y socializadora, por cuanto implica el menor de los grados posibles de injerencia del tercero ajeno al conflicto, y exige de las partes involucradas en la disputa la mayor disposición y esfuerzo para su resolución a través del pacto. La mediación es, en este sentido,

20 MARTÍ MIRAVALLS, J. Op. cit. 2003.

21 Si se opta por norma del Gobierno de Cantabria, sería aplicable la Disposición Final Primera de la LCCANT, sobre la competencia del Gobierno para desarrollar esta, pero sin plazo específico de actuación, a diferencia de lo previsto para las normas reguladoras del Registro de Cooperativas y del CCES. 
un instrumento coherente con la filosofía de colaboración que informa la dinámica del cooperativismo ${ }^{22}$. Como hemos visto, la LCCANT solamente menciona la conciliación y el arbitraje.

\section{Composición}

El Consejo Cántabro de la Economía Social estará formado por un total de catorce miembros. De ellos, seis lo serán en representación de la Administración y seis de las entidades asociativas representativas de la economía social y otros dos serán expertos de reconocido prestigio en la materia. La LCCANT concreta más esta composición:

Establece que dos miembros lo serán en función del cargo que desempeñan en la Administración de la Comunidad Autónoma y que son el presidente, cuyo cargo recaerá en el titular de la consejería competente en materia de economía social y el vicepresidente, que será el titular de la dirección general competente en la misma ${ }^{23}$.

Otros cuatro miembros serán designados por la consejería competente en materia de economía social. Es decir, la LCCANT no establece obligatoriamente que esos vocales sean miembros de la Administración de la Comunidad Autónoma, sino que son nombrados por esta, con lo cual, salvo que la norma reglamentaria de organización y funcionamiento, que se apruebe en su momento, limite quienes pueden ocupar esas vocalías nada impide que sean personas vinculadas a otras Administraciones, a la docencia, a la empresa, a las entidades asociativas o a cualquier área de actividad que pueda entenderse por la consejería competente para el nombramiento que pueden hacer aportaciones relevantes para el mundo de la economía social. En este sentido, creemos que la norma de organización y funcionamiento del CCES debería dejar abierta esta posibilidad para poder incluir entre sus miembros a las personas que mejor conocen este ámbito, independientemente de su procedencia profesional. La presencia de la consejería competente en la materia ya garantiza la asunción por parte del Gobierno de Cantabria de las políticas públicas que el Consejo entienda que su ejecución es necesaria.

22 FERNÁNDEZ CARBALLO-CALERO, P. y HERRERA PETRUS, C. "Métodos de resolución extrajudicial de conflictos en las sociedades cooperativas de Galicia». CIRIEC n. ${ }^{\circ} 19$. 2008. pp. 1-23.

23 En la actualidad, Dirección General de Trabajo. 
Seis miembros serán propuestos por las entidades asociativas de economía social de ámbito regional. El criterio para el reparto de estas vocalías será su representatividad e implantación territorial ${ }^{24}$.

Para asegurar que están presentes en el CCES las diferentes figuras de la denominada economía social de mercado, se exige que estén representadas las sociedades cooperativas, las sociedades laborales, los centros especiales de empleo y las empresas de inserción ${ }^{25}$.

Los criterios para el reparto de estas seis vocalías deberá ser objeto de regulación expresa en la norma de organización y funcionamiento del CCES. Para evitar conflictos posteriores entre las diferentes clases de empresas del sector, esta regulación deberá ser clara y concreta, respetando los criterios fijados, tanto sobre el grado de representatividad e implantación, como la exigencia de participación de los diferentes tipos de empresas citados en la LCCANT.

Por último, habrá dos miembros designados por el titular de la consejería competente por razón de la materia, entre personas de reconocido prestigio en el ámbito de la economía social. Estos dos vocales serán obligatoriamente expertos en la materia; pero, como decíamos anteriormente, no tienen por qué ser los únicos, ya que en el cupo de vocales de la Administración podrían tener cabida otras personas de perfil similar al exigido para estos dos miembros.

Como puede verse, se fija una representación paritaria entre la Administración y las entidades asociativas del sector, Además, se incluyen dos expertos que no representan a ninguna de las dos partes, por lo que no se rompe esa paridad.

Si consideramos el peso del sector sobre el total de miembros, tendremos que las entidades asociativas cuentan con el $42,86 \%$ de aquellos, lo que supone un grado considerablemente mayor que el que se otorga a las entidades representativas actualmente en el Consejo para el Fomento de la Economía Social que supone una representación del 30,64\%, como destaca Paz Canalejo ${ }^{26}$.

En la composición del CCES, si se compara con el previsto en la LES, se observa que no se incluye la presencia en el mismo de la aso-

24 Los criterios para la medición de la representatividad de las entidades asociativas de cooperativas, se regulan en el artículo 159.3 de la LCCANT. Para el resto de empresas que deben estar representadas en el Consejo no hay norma reguladora.

25 Desconocemos la existencia de organizaciones asociativas en el ámbito de la Comunidad Autónoma de Cantabria de centros especiales de empleo y de empresas de inserción.

26 PAZ CANALEJO, N. «Comentario sistemático a la Ley 5/2011, de Economía Social». Editorial Tirant lo Blanch. Colección Reformas. 2012, p. 242. 
ciación de entidades locales y de los sindicatos más representativos. El proyecto de ley remitido por el Gobierno al Parlamento de Cantabria no contemplaba la participación de los mismos. En este sentido, provoca cierta sorpresa la constatación de que en la tramitación parlamentaria ningún grupo presentase enmienda proponiendo la incorporación de estos agentes.

Finalmente, se prevé que actuará como secretario del CCES, con voz y sin voto, un funcionario de la consejería competente en materia de economía social, designado por el presidente del Consejo.

El mandato de los vocales tendrá una duración de cuatro años. Su nombramiento se realizará por el presidente, a propuesta de la Consejería competente o de las entidades asociativas de economía social. Cabe la renovación de los vocales. El Presidente y el Vicepresidente lo serán mientras ocupen el cargo por el que ostentan estas responsabilidades.

Como hemos dicho anteriormente, aún no se ha dictado una norma reglamentaria de organización y funcionamiento del CCES y la referida falta de inclusión en su composición de los agentes sociales más representativos de la Comunidad Autónoma de Cantabria puede ser uno de los motivos que esté retrasando su articulación. Y, decimos esto, a la luz de lo previsto en la Ley de Cantabria 4/2009, de 1 de diciembre, de participación institucional de los agentes sociales en el ámbito de la Comunidad Autónoma de Cantabria. Se indica en su artículo 1 que el objeto de la misma es establecer un marco jurídico que constituya la garantía de la participación institucional de las organizaciones sindicales y empresariales en el ámbito de los organismos y entidades públicas que conforman la Administración de la Comunidad Autónoma de Cantabria, para el ejercicio de todas las funciones, tareas y actividades de promoción y defensa de sus intereses y de cualesquiera otras de carácter general que redunden en beneficio del desarrollo social y económico colectivo. En el ámbito de intervención, se cita expresamente en el artículo 2.1.a) a la economía social.

Si este es uno de los motivos que están paralizando la creación del CCES, algo que desconocemos, se debe tomar una decisión, cuanto antes, al respecto. Bien, crearlo como prevé la LCCANT en su redacción actual o modificar de forma inmediata la misma para dar cabida a los agentes sociales más representativos y dictar después la norma de desarrollo necesaria para la efectiva entrada en funcionamiento del CCES; pero, lo único que no puede ocurrir es que se siga sin actuar al respecto; $y$, en consecuencia, el Consejo no comience su andadura.

Nos consta que la Administración de la Comunidad Autónoma se reúne regularmente con las asociaciones de empresas de economía so- 
cial para informar sobre temas de su interés (subvenciones, estudio de posibles modificaciones normativas...) lo cual, ante la falta de Consejo es una actitud muy loable de los responsables de la Administración en materia de economía social, pero es preciso que estas actuaciones se revistan de un halo institucional, en el seno del CCES.

\section{Funcionamiento}

El Consejo funcionará en pleno, sin perjuicio de que puedan crearse comisiones de trabajo para materias específicas, lo que será necesario para un funcionamiento correcto de este órgano, conforme a lo previsto en la normativa que se apruebe reglamentariamente.

No se hacen previsiones sobre la financiación del CCES en el capítulo dedicado a este en la LCCANT. Nos referimos a la financiación de las actividades que le son propias, ya que los cargos del Consejo, entendemos, que no deben ser remunerados.

Tan sólo en el artículo 97 de la LCCANT, se hace una indicación al respecto, al establecer las condiciones de adjudicación del haber social en caso de liquidación de las sociedades cooperativas. Prevé que el fondo de promoción y educación y los activos sobrantes después de seguir el procedimiento de adjudicación previsto en dicho artículo, se destinará al CCES si no se designa como beneficiaria de los mismos a una entidad asociativa de cooperativas. Ante la falta de regulación en la ley, el decreto que regule el Consejo deberá realizar previsiones sobre la asignación de medios materiales y humanos de este, que perfectamente pueden ser puestos a disposición por la Consejería de Economía, Hacienda y Empleo.

\section{Conclusiones}

Como hemos reiterado, resulta evidente que es necesario un desarrollo reglamentario del capítulo III del Título III de la LCCANT. Es precisa una norma de organización y funcionamiento del CCES para que este pueda empezar a trabajar. La decisión de adoptar esta medida, de forma inmediata o seguir posponiéndola en el tiempo, y continuar incumpliendo la obligación que le impone la ley, queda en manos del Gobierno de Cantabria, que tiene con este asunto una oportunidad para demostrar el grado de interés real que se toma en favor de las políticas de fomento y difusión de la economía social. Recordemos que el decreto debería estar aprobado antes de enero de 2015. Si existe el 
obstáculo que referíamos anteriormente para su creación; podría optarse, incluso, por crear un consejo de esta naturaleza por un decreto que no se dicte en desarrollo de la LCCANT y cree un órgano diferente al previsto en la misma y que dé entrada a los agentes sociales; pero, un órgano con amplias funciones en materia de fomento y difusión de la economía social y con una participación destacada de la representación del sector.

Creemos que la existencia de este Consejo, en la formulación que se considere más adecuada y un trabajo bien realizado por el mismo, contribuiría de forma importante a facilitar la visibilidad, hoy más bien escasa, por parte de la sociedad del sector de la economía social, además de ser un instrumento vital para la promoción de esta forma de hacer empresa.

Para que el CCES logre sus objetivos es necesario el compromiso de todos los agentes implicados (Administraciones, empresas, entidades asociativas de estas, Universidad,... y, en su caso, agentes sociales) y la voluntad de todos para mejorar el panorama de la economía social en Cantabria. La inclusión de todos ellos en este órgano supondría un paso claro en esa línea de colaboración necesaria de un amplio espectro de la sociedad, con un objetivo común: la promoción de la economía social.

\section{Bibliografía}

Calvo Ortega, R. «Las figuras de la economía social en la Constitución Española de 1978». CIRIEC-España, n. ${ }^{\circ}$ 47. 2003. Pp. 159-174.

Calvo Ortega, R., «Sociedades Laborales». Cuadernos Civitas. Editorial Aranzadi. Cizur Menor 2013.

ChAves, R.: «La loi espagnole de l'économie sociale», Revue Internationale de I'Économie Sociale, 2011.

Fernández Carballo-Calero, P. y Herrera Petrus, C. «Métodos de resolución extrajudicial de conflictos en las sociedades cooperativas de Galicia». CIRIEC n. ${ }^{19}$. 2008 pp. 1-23.

Martí Miravalls, J. «El arbitraje cooperativo. El caso valenciano». CIRIEC n. ${ }^{\circ} 14$. 2003. pp. 83-129.

Montesinos OltRA, S., «La Ley de Economía Social, interés general y regímenes tributarios especiales». CIRIEC-España, Revista Jurídica n. ${ }^{\circ} 23.2012$, pp. 1-27.

Paz Canalejo, N. «Comentario sistemático a la Ley 5/2011, de Economía Social». Editorial Tirant lo Blanch. Colección Reformas. 2012. 